\title{
IDENTIFICAÇÃO DE IMPACTOS AMBIENTAIS NAS ÁGUAS DO TRECHO PERENIZADO DO RIO PIANCÓ
}

\author{
Fernanda Carolina Monteiro Ismael ${ }^{* *}$ \\ José Cleidimário Araújo Leite ${ }^{* * * *}$ \\ Daniele Aparecida Monteiro Ismael ${ }^{* * * * * *}$ \\ Elton Ferreira da Silva ${ }^{* * * * * * * *}$ \\ Graziela Pinto de Freitas ${ }^{* * * * * * * * * * * * *}$ \\ Thâmara Martins Ismael de Sousa ${ }^{* * * * * * * * * * * *}$
}

RESUMO: Neste trabalho teve-se por objetivo identificar os impactos ambientais nas águas do trecho perenizado do rio Piancó. Para tanto, um diagnóstico ambiental simplificado da área foi realizado, por meio de pesquisas bibliográficas, visitas de campo, geoprocessamento, fotodocumentação e consultas a órgãos públicos, a partir do qual foram identificadas as atividades antrópicas com potencial impactante das águas do rio. Foram identificados os impactos por meio dos métodos Ad Hoc, Check Lists e Matriz de Interação. De acordo com os resultados, obtiveram-se 12 tipos de atividades antrópicas de alto potencial impactante, com predominância da agricultura, em $27,9 \%$ do total. Identificaram-se 132 impactos ambientais nas águas do rio. A atividade antrópica "responsável" pelo maior número de impactos ambientais significativos foi a urbanização. Por fim, espera-se que este estudo sirva como subsídio para o planejamento e implantação de políticas públicas voltadas à gestão hídrica e à sustentabilidade ambiental da região, e ainda venha a contribuir para 0 acervo bibliográfico técnico e científico sobre o tema, bastante carente na literatura, em especial para a área de estudo.

PALAVRAS-CHAVE: Estudos e relatórios ambientais; Meio ambiente; Recursos hídricos.

\footnotetext{
"Mestre em Sistemas Agroindustriais pela Universidade Federal de Campina Grande (UFCG). Docente titular do Instituto Federal de Educação, Ciência e Tecnologia da Paraíba, Brasil.

E-mail: fernnanda_monyeiro@hotmail.com

** Doutor em Engenharia de Processos pela Universidade Federal de Campina Grande. Docente Adjunto III da Universidade Federal de Campina Grande (UFCG), Brasil.

**** Mestrado no Programa de Pós-Graduação em Tecnologias Energéticas e Nucleares - PROTEN/UFPE

**** Graduação em Engenharia Ambiental pela Universidade Federal de Campina Grande, (UFCG), Brasil

****** Discente do mestrado em Energias Renováveis pela Universidade Federal da Paraíba (UFCG), Brasil.

${ }^{* * * * * * *}$ Doutoranda em Engenharia Civil e Ambiental pela Universidade Federal da Paraíba (UFPB), Brasil.
} 


\title{
IDENTIFICATION OF ENVIRONMENTAL IMPACTS ON THE PERMANENT WATER STRETCH OF THE RIVER PIANCÓ
}

\begin{abstract}
Environmental impacts on the water of the permanent water stretch of the river Piancó are identified. A simplified environmental diagnosis was performed by bibliographical research works, field work, geoprocessing, photo-documents and consultation in public data bases. Anthropic activities with the impacting potential on the river were identified. Impacts were identified by Ad Hoc, Check Lists and Interaction Matrix. Results revealed 12 types of anthropic activities with high impacting capacity, with $27.9 \%$ predominance in agriculture. Further, environmental impacts were identified in the water of the river. The anthropic activity which caused the greatest amount of significant environmental impacts was urbanization. Current analysis may serve as a subsidy for the planning and implantation of public policies for water management and environmental sustainability of the region. It may also contribute towards a technical and scientific bibliographic analysis on the theme, lacking in the literature.
\end{abstract}

KEY WORDS: Environmental studies and reports; Environment; Water resources.

\section{INTRODUÇÃO}

A água é considerada um dos recursos naturais mais "cobiçados" pela humanidade, devido à sua importância para a sobrevivência humana e dos demais seres vivos, assim como pela sua insuficiência, em termos qualitativos e/ou quantitativos, em várias regiões do planeta Terra, principalmente nos locais onde as atividades antrópicas utilizam esse recurso sob manejo inadequado (BARROS; AMIN, 2008).

Segundo a Agência Nacional de Águas (ANA, 2012), o Brasil é um país privilegiado quanto à disponibilidade de água por deter $12 \%$ da água doce do mundo. Apesar desse cenário, a distribuição inadequada da água colabora para a carência desse recurso em várias regiões brasileiras, entre as quais destaca-se o semiárido nordestino.

Além da distribuição inadequada da água, de acordo com Pereira (2004), ainda é importante que se considerem as diversas atividades potencialmente 
impactantes dos recursos hídricos, entre elas destacam-se aquelas que realizam a destinação ambientalmente inadequada dos resíduos sólidos e líquidos, a exemplo da mineração e das atividades industriais.

Nesse cenário, o rio Piancó, pertencente à Bacia Hidrográfica do Rio Piranhas - Açu, destaca-se por estar inserido em uma região em que as atividades são, predominantemente, agroindustriais, que estão entre as que mais consomem água, tanto na produção primária, quanto na agroindústria. Este rio possui um trecho que foi perenizado com a implementação do Sistema Hídrico Curema - Mãe D’Água no ano de 1953, localizada no município de Coremas (PB), a partir do qual tal trecho tem início, passa pelo município de Cajazeirinhas (PB), e segue até o município de Pombal (PB), onde deságua no rio Piranhas, há cerca de 5,0 km de sua área urbana.

Sabe-se que a realização de atividades antrópicas em leitos de rios, ou próximo a eles, intensifica as alterações na qualidade dos recursos hídricos (VANZELA; HERNANDEZ; FRANCO, 2010; PINHEIRO et al., 2014). Sendo assim, presume-se que a região do rio Piancó encontra-se vulnerável a sofrer impactos ambientais, em especial sobre os recursos hídricos.

Com base no exposto, pressupõe-se que as práticas citadas e outras atividades antrópicas têm o potencial de afetar o equilíbrio ambiental do meio aquático na região em questão, o que pode acarretar impactos no abastecimento humano e animal. Além disso, as atividades que fazem uso do citado corpo hídrico como, por exemplo, as agroindustriais, podem ser comprometidas por utilizar água em seus processos produtivos, de qualidade inferior à requerida.

Diante deste contexto, neste trabalho propôs-se a identificação dos impactos ambientais nas águas do trecho perenizado do rio Piancó. Com a conclusão deste estudo, espera-se que os resultados obtidos possam contribuir para a elaboração de um planejamento estratégico voltado à gestão e ao gerenciamento das águas do rio Piancó, de forma que o uso e a ocupação da região estudada passem a ser realizados segundo os preceitos do desenvolvimento sustentável. 


\section{MATERIAL E MÉTODOS}

\subsection{LOCALIZAÇÃO DA ÁREA DE ESTUDO}

A região que compreende a área de estudo encontra-se localizada no sertão da Paraíba, na Sub-bacia do rio Piancó, e engloba os municípios de Coremas (PB), Cajazeirinhas (PB) e Pombal (PB), conforme apresentado na Figura 1.

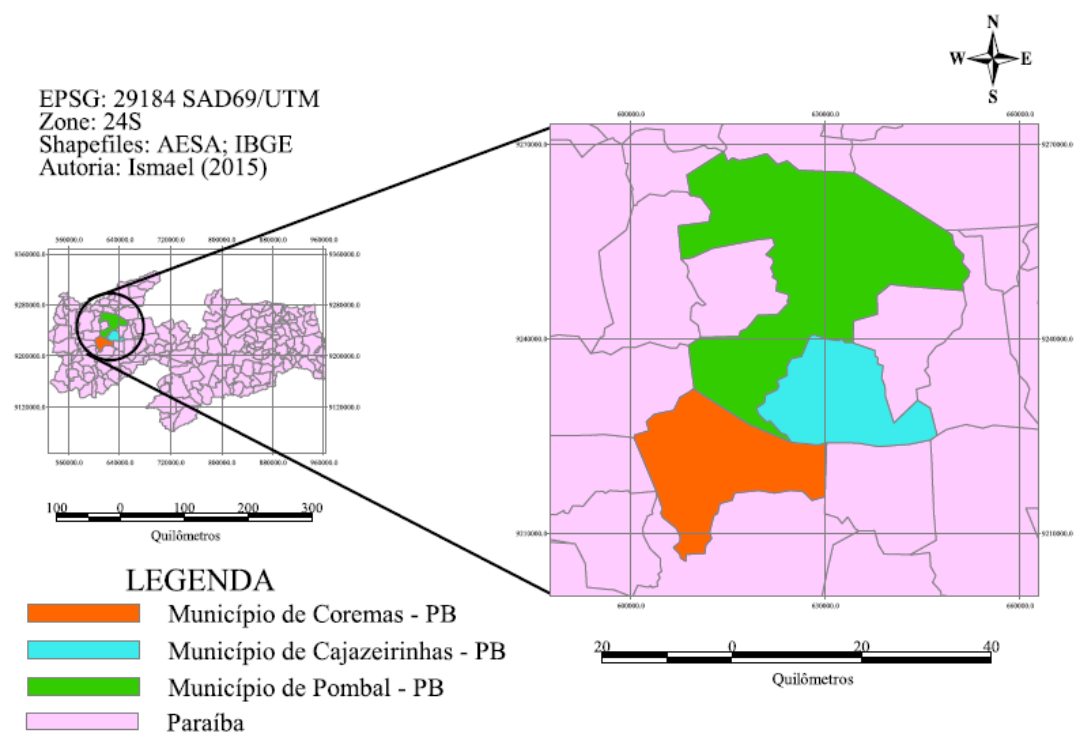

Figura 1. Mapa de localização da área de estudo Fonte: Autoria própria, 2015.

\subsection{DIAGNÓSTICO AMBIENTAL SIMPLIFICADO DA ÁREA DE INFLUÊNCIA}

O diagnóstico ambiental simplificado foi realizado na área de influência do estudo a partir de visitas técnicas a campo, entrevistas informais e fotodocumentação, e ainda por meio de ferramentas de geoprocessamento, consultas a trabalhos técnicos e científicos e a órgãos e instituições governamentais e não governamentais.

$\mathrm{Na}$ elaboração do diagnóstico foram descritos os componentes/fatores 
ambientais e suas relações e/ou interações para os meios físico, biótico e antrópico, conforme Brasil (1986) e Sánchez (2008), como descrito abaixo:

- Meio Físico: clima, geologia, geomorfologia, solos, relevo, recursos hídricos, uso e ocupação do solo e paisagem.

- Meio Biótico: cobertura vegetal e fauna.

- Meio Antrópico: população, aspectos sociais, economia local e atividades culturais.

\subsection{LEVANTAMENTO DAS ATIVIDADES ANTRÓPICAS COM POTENCIAL IMPACTANTE NA ÁREA DE INFLUÊNCIA}

A identificação das atividades antrópicas com potencial impactante na área de influência foi realizada por meio de visitas de campo durante a elaboração do diagnóstico ambiental simplificado. Tais atividades foram catalogadas e caracterizadas a partir do uso de Sistema de Posicionamento Global (GPS), fotodocumentação e entrevistas informais aos moradores da área de estudo.

\subsection{IDENTIFICAÇÃO DOS ASPECTOS E IMPACTOS AMBIENTAIS NAS ÁGUAS DO RIO}

A identificação dos aspectos e impactos ambientais nas águas do rio foi realizada por meio de visitas de campo in loco e da utilização dos métodos de avaliação de impactos ambientais (AIA): Ad Hoc (Método Espontâneo), Check Lists (Listagens de Verificação) e Matriz de Interação, de acordo com Fogliatti; Filippo; Goudard (2004); Sánchez (2008); e Cunha; Guerra (2010).

Foram identificados os aspectos ambientais, que são mecanismos que ligam a causa (atividade antrópica) ao efeito (alteração ambiental) (SÁNCHEZ, 2008), relacionados a cada atividade antrópica.

Identificaram-se in loco os impactos ambientais ocorrentes, que já aconteceram ou estavam a acontecer, e verificados os impactos potenciais: aqueles 
de provável ocorrência e que são previstos/antevistos por meio de análise da relação entre causa (ação antrópica) e efeito (alteração ambiental), seja nas visitas a campo ou por meio dos métodos de AIA. Para tanto, fez-se uso das informações obtidas no diagnóstico ambiental simplificado e nas atividades antrópicas identificadas na área de influência do estudo.

\section{RESULTADOS E DISCUSSÃO}

\subsection{DIAGNÓSTICO AMBIENTAL SIMPLIFICADO DA ÁREA DE INFLUÊNCIA}

\subsubsection{Meio físico}

No Quadro 1, apresentam-se informações sobre algumas características climáticas dos municípios de Coremas (PB), Cajazeirinhas (PB) e Pombal (PB).

Quadro 1. Características climáticas da área de estudo

\begin{tabular}{|l|l|l|l|}
\hline Característica & \multicolumn{1}{|c|}{ Coremas (PB) } & \multicolumn{1}{c|}{ Cajazeirinhas (PB) } & \multicolumn{1}{c|}{ Pombal (PB) } \\
\hline Tipo de clima & $\begin{array}{l}\text { Clima semiárido quente e } \\
\text { seco }\end{array}$ & $\begin{array}{l}\text { Clima semiárido quente } \\
\text { e seco }\end{array}$ & $\begin{array}{l}\text { Clima semiárido } \\
\text { quente e seco }\end{array}$ \\
\hline Temperatura & $\begin{array}{l}\text { Mínima: } 23^{\circ} \mathrm{C} \\
\text { Máxima: } 30^{\circ} \mathrm{C}\end{array}$ & $\begin{array}{l}\text { Mínima: } 23^{\circ} \mathrm{C} \\
\text { Máxima: } 30^{\circ} \mathrm{C}\end{array}$ & $\begin{array}{l}\text { Mínima: } 21,3{ }^{\circ} \mathrm{C} \\
\text { Máxima: } 33,2^{\circ} \mathrm{C}\end{array}$ \\
\hline Média: $26,5^{\circ} \mathrm{C}$ & Média: $26,5^{\circ} \mathrm{C}$ & Média: $27^{\circ} \mathrm{C}$ \\
\hline Pluviométrica & $\begin{array}{l}\text { Variação entre } 342,7 \text { e } 1837,7 \\
\mathrm{~mm} / \text { ano }\end{array}$ & $\begin{array}{l}\text { Variação entre } 400 \text { e } 600 \\
\mathrm{~mm} / \text { ano }\end{array}$ & $\begin{array}{l}\text { Variação entre } 601 \\
\text { e } 800 \mathrm{~mm} / \text { ano }\end{array}$ \\
\hline
\end{tabular}

Fonte: Adaptado de CPRM (2005a); CPRM (2005b); CPRM (2005c); Lima e Leite (2011).

No que se refere aos aspectos geológicos do município de Coremas (PB), de acordo com a CPRM (2005b), o material geológico predominante é o Suíte Várzea Alegre: ortognaisse tonalítico-granodiorítico e migmatito (2098 Ma U-Pb).

No que tange ao município de Cajazeirinhas (PB), segundo a Companhia de Pesquisa de Recursos Minerais (CPRM, 2005a), o referido município é constituído, predominantemente, de materiais do tipo Suíte Várzea Alegre: migmatito bandado e 
nebulítico com mesossoma granodiorítico (2349 Ma U-Pb).

Segundo a CPRM (2005c), a geologia do município de Pombal (PB) é constituída, predominantemente, pelo material denominado Suíte Calcialcalina de Médio a Alto Potássio Itaporanga $(\mathrm{cm})$, composto por granito e granodiorito porfirítico associado a diorito (588 Ma U-Pb).

Os aspectos geomorfológicos dos municípios de Coremas (PB), Cajazeirinhas $(\mathrm{PB})$ e Pombal $(\mathrm{PB})$ encontram-se inseridos, predominantemente, em depressões sertanejas com formas tabulares (AESA, 2015).

Os solos da área de estudo são, predominantemente, do tipo Bruno Não Cálcico, de acordo com a EMBRAPA (2015).

O relevo dos municípios de Coremas (PB) e Cajazeirinhas (PB) enquadra-se na denominada "Planície Sertaneja", sendo esta constituída por extenso pediplano arrasado, onde ocorrem elevações residuais alongadas e alinhadas com o trend da estrutura geológica regional (CPRM, 2005a; CPRM, 2005b).

No que se refere ao município de Pombal (PB), segundo a CPRM (2005c), o relevo está inserido na unidade geoambiental da Depressão Sertaneja, caracterizada por uma superfície de pediplanação monótona, relevo predominantemente suaveondulado, cortada por vales estreitos, com vertentes dissecadas.

No que tange aos corpos d'água superficiais da área de estudo, destacam-se os rios Piancó (que possui o trecho perenizado inserido no território dos municípios de Coremas (PB), Cajazeirinhas (PB) e Pombal (PB)) e Piranhas (que se localiza, predominantemente, no município de Pombal (PB)) e o sistema Curema - Mãe D’Água (localizado no município de Coremas (PB)).

Conforme pode ser observado na Figura 2, o rio Piancó está localizado nos domínios da Sub-Bacia do rio Piancó e o trecho do rio Piranhas situa-se nas regiões do Alto e Médio Curso do rio Piranhas. 
EPSG: 29184 SAD69/UTM

Zone: $24 \mathrm{~S}$

Shapefiles: AESA; IBGE

Autoria: Ismael (2015)
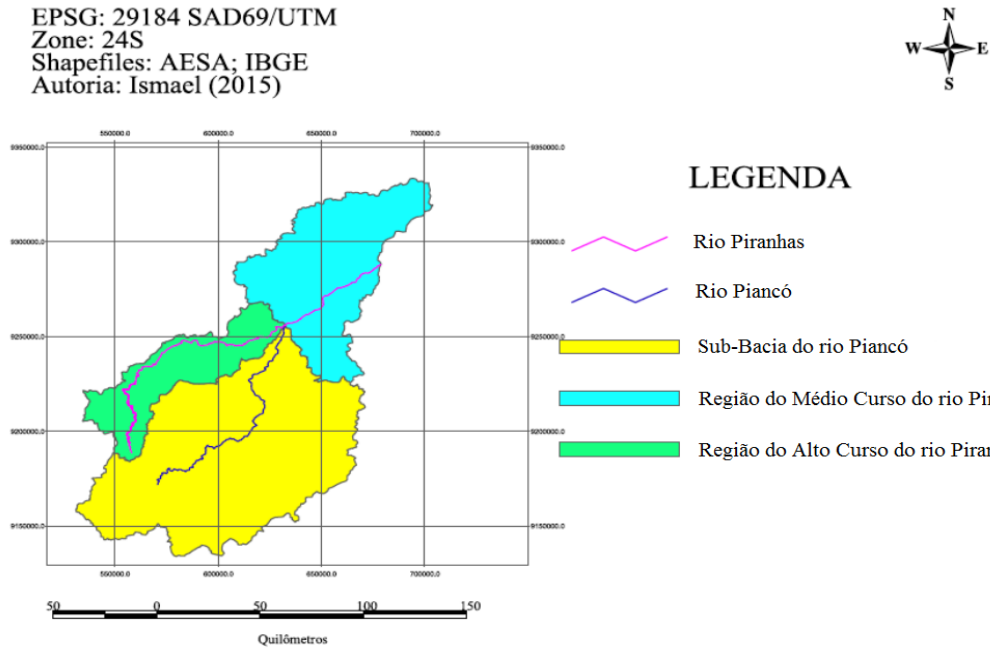

\section{LEGENDA}

Rio Piranhas

Rio Piancó

Sub-Bacia do rio Piancó

Região do Médio Curso do rio Piranhas

Região do Alto Curso do rio Piranhas

Figura 2. Mapa das sub-bacias e regiões hidrográficas dos rios Piancó e Piranhas Fonte: Autoria própria, 2015.

No que tange à qualidade da água do rio Piancó, no Quadro 2 apresentam-se dados, fornecidos pela Superintendência de Administração do Meio Ambiente (SUDEMA, 2014), referentes a um trecho do referido rio, localizado a 100 metros à jusante da descarga da tubulação de energia da Companhia Hidrelétrica do São Francisco (CHESF) no município de Coremas (PB).

Quadro 2. Dados de qualidade da água do rio Piancó

\begin{tabular}{|l|c|c|}
\hline \multicolumn{1}{|c|}{ Parâmetro } & $\begin{array}{c}\text { Valor obtido no rio Pian- } \\
\text { có (SUDEMA, 2014) }\end{array}$ & $\begin{array}{c}\text { Valor de referência para rios de } \\
\text { Classe 2 (BRASIL, 2005) }\end{array}$ \\
\hline Cor $(\mathrm{mg} \mathrm{Pt/L)}$ & 25 & Até 75 \\
\hline Turbidez (UT) & 7 & Até 100 \\
\hline $\mathrm{pH}$ & 7,93 & 6 a 9 \\
\hline Salinidade (\%) & 0 & Igual ou inferior a 0,5 \\
\hline Sólidos dissolvidos totais $(\mathrm{mg} / \mathrm{L})$ & 175 & Até 500 \\
\hline OD $\left(\mathrm{mg} / \mathrm{L} \mathrm{O}_{2}\right)$ & 4,8 & Superior a 5 \\
\hline DBO $\left(\mathrm{mg} / \mathrm{L} \mathrm{O}_{2}\right)$ & 0,9 & Até 5 \\
\hline $\begin{array}{l}\text { Coliformes termotolerantes (unida- } \\
\text { des) }\end{array}$ & 375 & Até 1000 \\
\hline
\end{tabular}

Fonte: Autoria própria (2015). 
Ao se analisar os dados apresentados no Quadro 2, percebe-se que praticamente todos os parâmetros observados encontram-se em conformidade com os valores de referência estabelecidos na Resolução CONAMA n ${ }^{0}$ 357, de 17 de março de 2005, exceto o valor obtido para o parâmetro oxigênio dissolvido, um pouco inferior ao permitido.

\subsubsection{Meio biótico}

No que tange à vegetação do município de Cajazeirinhas (PB), segundo a CPRM (2005a), há a predominância de vegetação de pequeno porte, típica da caatinga xerofítica, sendo comum a presença de espécies vegetais dos tipos cactáceas, arbustos e árvores de pequeno a médio porte.

A vegetação predominante nos municípios de Pombal $(\mathrm{PB})$ e de Coremas (PB) é do tipo Caatinga Hiperxerófila com trechos de Floresta Caducifólia (CPRM, 2005b; CPRM, 2005c).

\subsubsection{Meio antrópico}

No tocante à população da área de estudo, no Quadro 3 apresentamse dados demográficos dos municípios de Coremas (PB), Cajazeirinhas (PB) e de Pombal (PB), referentes ao ano de 2010.

Quadro 3. Dados populacionais da área de estudo

\begin{tabular}{|l|r|r|r|}
\hline \multicolumn{1}{|c|}{$\begin{array}{c}\text { População referente ao ano } \\
\mathbf{2 0 1 0}\end{array}$} & Coremas (PB) & Cajazeirinhas (PB) & \multicolumn{1}{c|}{ Pombal (PB) } \\
\hline Urbana (hab) & 11.419 & 1.000 & 25.753 \\
\hline Rural (hab) & 3.730 & 2.033 & 6.357 \\
\hline Total (hab) & 15.149 & 3.033 & 32.110 \\
\hline Homens (hab) & 7.421 & 1.548 & 15.381 \\
\hline Mulheres (hab) & 7.728 & 1.485 & 16.729 \\
\hline Densidade demográfica $\left(\mathrm{hab} / \mathrm{km}^{2}\right)$ & 39,92 & 10,54 & 36,13 \\
\hline
\end{tabular}

Fonte: IBGE, 2010. 
De acordo com os dados apresentados no Quadro 3, percebe-se que Pombal (PB) é o município que possui população, 32.110 habitantes, seguido dos municípios de Coremas (PB) e Cajazeirinhas (PB), respectivamente. Com relação à densidade demográfica, o município que possui maior número de habitantes por unidade de área $\left(\mathrm{km}^{2}\right)$ é Coremas (PB), seguido, em respectivo, dos municípios de Pombal (PB) e Cajazeirinhas (PB).

\subsection{DIAGNÓSTICO DAS ATIVIDADES ANTRÓPICAS COM POTENCIAL IMPACTANTE NA ÁREA DE INFLUÊNCIA}

Na Figura 3 apresentam-se, em termos percentuais, as atividades com potencial impactante na área de influência do estudo.

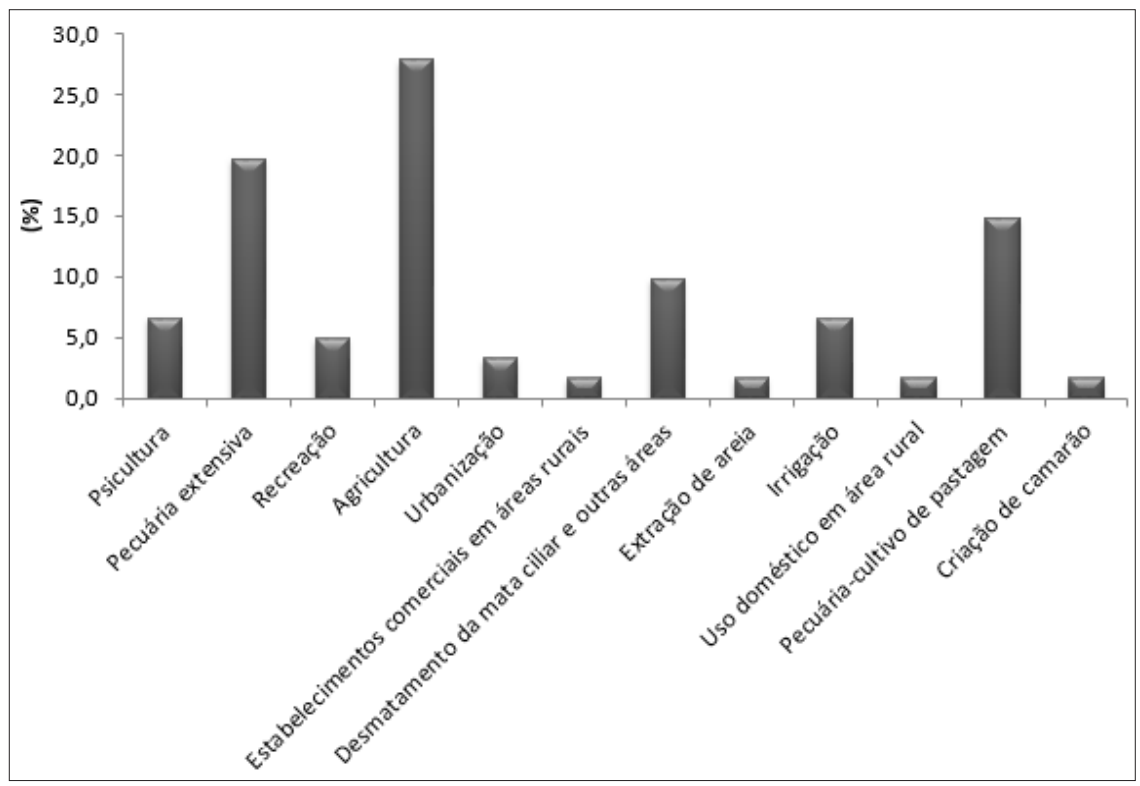

Figura 3. Atividades com potencial impactante na área de influência do estudo Fonte: Autoria própria, 2015.

Com base nas informações apresentadas na Figura 3, percebe-se que nas áreas visitadas foram constatados 12 tipos de atividades antrópicas com potencial impactante, em que se constatou um total de 61 atividades, sendo a agricultura 
predominante, representando $27,9 \%$ dos tipos de atividades verificadas, seguida pela pecuária extensiva, com 19,7\%, e da pecuária - cultivo de pastagem, com cerca de $15 \%$. Santos (2009) também destacou a agricultura como uma atividade com alto potencial de ocasionar impactos ambientais. Segundo o autor, as atividades agrícolas ocasionam diversos impactos ambientais devido, principalmente, a retirada da mata ciliar. Isto pode ser atribuído ao fato que parte dos trabalhadores agrícolas desconhece os riscos ambientais que algumas práticas ofertam aos ecossistemas.

\subsection{IDENTIFICAÇÃO DOS ASPECTOS E IMPACTOS AMBIENTAIS NAS ÁGUAS DO RIO}

Foram identificados diversos impactos ambientais nas águas do rio, resultantes das interações existentes entre as atividades/empreendimentos e o meio ambiente local, especialmente no fator ambiental água.

No Quadro 4 apresentam-se as atividades/empreendimentos e os respectivos aspectos e impactos ambientais identificados, ocorrentes ou potenciais, na área de influência direta do estudo.

Quadro 4. Aspectos e impactos ambientais identificados nas águas do rio

(Continua)

\begin{tabular}{|c|c|c|}
\hline $\begin{array}{c}\text { Atividade } \\
\text { Empreendimento }\end{array}$ & Aspecto ambiental & Impacto ambiental na água ${ }^{1}$ \\
\hline \multirow[t]{4}{*}{ Piscicultura } & Utilização/Consumo de água & Redução da disponibilidade de água \\
\hline & $\begin{array}{c}\text { Destinação ambientalmente } \\
\text { inadequada de resíduos líquidos } \\
\text { e sólidos }\end{array}$ & $\begin{array}{l}\text { Aumento no risco de escassez hídrica } \\
\text { Poluição hídrica } \\
\text { Contaminação hídrica } \\
\text { Eutroficação (aumento da eutrofização pela ação } \\
\text { antrópica) } \\
\text { Aumento da turbidez } \\
\text { Alteração na qualidade da água } \\
\text { Efeitos dos odores desagradáveis } \\
\text { Aumento no risco de degradação do corpo hídrico } \\
\text { Limitação de uso da água para fins mais nobres }\end{array}$ \\
\hline & Criação de espécies exóticas & $\begin{array}{l}\text { Risco de contaminação do meio aquático por espécies } \\
\text { exóticas }\end{array}$ \\
\hline & Desperdício de água & Aumento do volume demandado de água \\
\hline
\end{tabular}


(Continua)

\begin{tabular}{|c|c|c|}
\hline \multirow[t]{3}{*}{$\begin{array}{c}\text { Atividade } \\
\text { Empreendimento }\end{array}$} & Aspecto ambiental & Impacto ambiental na água ${ }^{1}$ \\
\hline & & Redução da disponibilidade de água \\
\hline & & Aumento no risco de escassez hídrica \\
\hline \multirow[t]{8}{*}{ Pecuária extensiva } & $\begin{array}{l}\text { Utilização de água para desseden- } \\
\text { tação animal /Consumo de água }\end{array}$ & Redução da disponibilidade de água \\
\hline & \multirow{6}{*}{$\begin{array}{l}\text { Geração/Lançamento de resíduos } \\
\text { sólidos e líquidos na água (ricos } \\
\text { em nutrientes) }\end{array}$} & Poluição hídrica \\
\hline & & Contaminação hídrica \\
\hline & & Eutroficação \\
\hline & & Aumento da turbidez \\
\hline & & Efeitos dos odores desagradáveis \\
\hline & & Alteração na qualidade da água \\
\hline & Adoção do modelo extensivo & Assoreamento \\
\hline \multirow{9}{*}{$\begin{array}{l}\text { Pecuária - cultivo de } \\
\text { pastagem }\end{array}$} & \multirow{6}{*}{$\begin{array}{l}\text { Geração/Lançamento de resíduos } \\
\text { sólidos e líquidos na água (ricos } \\
\text { em nutrientes) }\end{array}$} & Poluição hídrica \\
\hline & & Contaminação hídrica \\
\hline & & Eutroficação \\
\hline & & Aumento da turbidez \\
\hline & & Alteração na qualidade da água \\
\hline & & Intrusão visual no leito do rio \\
\hline & \multirow{3}{*}{$\begin{array}{c}\text { Utilização de agroquímicos na } \\
\text { pastagem }\end{array}$} & Poluição hídrica \\
\hline & & Contaminação hídrica \\
\hline & & Eutroficação \\
\hline \multirow[t]{6}{*}{ Recreação } & \multirow{6}{*}{$\begin{array}{l}\text { Geração/Lançamento de resíduos } \\
\text { sólidos e líquidos na água }\end{array}$} & Poluição hídrica \\
\hline & & Contaminação hídrica \\
\hline & & Eutroficação \\
\hline & & Poluição visual na água \\
\hline & & Alteração na paisagem natural do rio \\
\hline & & Alteração na qualidade da água \\
\hline \multirow[t]{6}{*}{ Agricultura } & \multirow{6}{*}{$\begin{array}{l}\text { Geração/Lançamento de resíduos } \\
\text { sólidos e líquidos (nutrientes e/ou } \\
\text { defensivos agrícolas) na água }\end{array}$} & Poluição hídrica \\
\hline & & Contaminação hídrica \\
\hline & & Eutroficação \\
\hline & & Aumento da turbidez \\
\hline & & Efeitos de odores desagradáveis \\
\hline & & Alteração na qualidade da água \\
\hline \multirow[t]{4}{*}{ Urbanização } & \multirow{4}{*}{$\begin{array}{l}\text { Utilização de água/Consumo de } \\
\text { água } \\
\text { Desperdício de água }\end{array}$} & Redução da disponibilidade de água \\
\hline & & Aumento no risco de escassez hídrica \\
\hline & & Aumento do volume demandado de água \\
\hline & & Redução da disponibilidade de água \\
\hline
\end{tabular}


Fernanda Ismael, Leite, Daniele Ismael, Silva, Freitas, Sousa 1011

(Continua)

\begin{tabular}{|c|c|c|}
\hline \multirow[t]{6}{*}{$\begin{array}{c}\text { Atividade } \\
\text { Empreendimento }\end{array}$} & \multirow[t]{2}{*}{ Aspecto ambiental } & Impacto ambiental na água ${ }^{1}$ \\
\hline & & Aumento no risco de escassez hídrica \\
\hline & \multirow{4}{*}{$\begin{array}{l}\text { Tráfego de veículos e pessoas } \\
\text { Impermeabilização de áreas } \\
\text { urbanas }\end{array}$} & Assoreamento \\
\hline & & Aumento nos eventos de inundação e/ou alagamento \\
\hline & & Aumento da turbidez \\
\hline & & Alteração na qualidade da água \\
\hline & \multirow{10}{*}{$\begin{array}{c}\text { Destinação ambientalmente } \\
\text { inadequada de resíduos líquidos: } \\
\text { esgotos domésticos, industriais } \\
\text { e outros }\end{array}$} & Poluição hídrica \\
\hline & & Contaminação hídrica \\
\hline & & Eutroficação \\
\hline & & Alteração na paisagem natural do rio \\
\hline & & Poluição visual nas águas do rio \\
\hline & & Aumento da turbidez \\
\hline & & Efeitos de odores desagradáveis \\
\hline & & Alteração na qualidade da água \\
\hline & & Limitação de uso da água para fins mais nobres \\
\hline & & $\begin{array}{l}\text { Degradação de parte do corpo hídrico (trecho urbano } \\
\text { e suas proximidades) }\end{array}$ \\
\hline & \multirow{10}{*}{$\begin{array}{c}\text { Destinação ambientalmente } \\
\text { inadequada de resíduos sólidos }\end{array}$} & Poluição hídrica \\
\hline & & Contaminação hídrica \\
\hline & & Eutroficação \\
\hline & & Aumento da turbidez \\
\hline & & Alteração na qualidade da água \\
\hline & & Efeitos de odores desagradáveis \\
\hline & & Alteração na paisagem natural do rio \\
\hline & & Poluição visual nas águas do rio \\
\hline & & $\begin{array}{l}\text { Degradação de parte do corpo hídrico (trecho urbano } \\
\text { e suas proximidades) }\end{array}$ \\
\hline & & Limitação de uso da água para fins mais nobres \\
\hline \multirow{7}{*}{$\begin{array}{l}\text { Desmatamento da mata } \\
\text { ciliar e outras áreas }\end{array}$} & \multirow{7}{*}{$\begin{array}{l}\text { Retirada da vegetação/Exposição } \\
\text { do solo }\end{array}$} & Poluição hídrica \\
\hline & & Contaminação hídrica \\
\hline & & Assoreamento \\
\hline & & Eutroficação \\
\hline & & Aumento da turbidez \\
\hline & & Alteração na qualidade da água \\
\hline & & $\begin{array}{l}\text { Alteração na velocidade de escoamento e na vazão } \\
\text { do rio }\end{array}$ \\
\hline
\end{tabular}


(Continua)

\begin{tabular}{|c|c|c|}
\hline \multirow[t]{7}{*}{$\begin{array}{c}\text { Atividade } \\
\text { Empreendimento }\end{array}$} & Aspecto ambiental & Impacto ambiental na água ${ }^{1}$ \\
\hline & & Aumento do risco de enchentes \\
\hline & & Aumento no risco de degradação do corpo hídrico \\
\hline & Movimentação/Circulação de & Assoreamento \\
\hline & máquinas pesadas & $\begin{array}{l}\text { Alteração na velocidade de escoamento e na vazão } \\
\text { do rio }\end{array}$ \\
\hline & & Aumento da turbidez \\
\hline & & Alteração na qualidade da água \\
\hline \multirow[t]{8}{*}{ Extração de areia } & \multirow{4}{*}{$\begin{array}{l}\text { Risco de vazamentos de óleos e } \\
\text { graxas }\end{array}$} & Poluição hídrica \\
\hline & & Contaminação hídrica \\
\hline & & Alteração na qualidade da água \\
\hline & & Aumento no risco de degradação do corpo hídrico \\
\hline & \multirow{4}{*}{$\begin{array}{l}\text { Remoção de sedimentos no leito } \\
\text { do rio }\end{array}$} & $\begin{array}{l}\text { Alteração na velocidade de escoamento e na vazão } \\
\text { do rio }\end{array}$ \\
\hline & & Aumento da turbidez \\
\hline & & Alteração na qualidade da água \\
\hline & & Aumento no risco de degradação do corpo hídrico \\
\hline \multirow[t]{9}{*}{ Irrigação } & \multirow{6}{*}{$\begin{array}{l}\text { Utilização de água/Consumo de } \\
\text { água: agricultura e pecuária }\end{array}$} & Redução da disponibilidade de água \\
\hline & & Risco de salinização da água \\
\hline & & Risco de poluição/contaminação hídrica \\
\hline & & Alteração na qualidade da água \\
\hline & & Aumento no risco de escassez hídrica \\
\hline & & Aumento no risco de degradação do corpo hídrico \\
\hline & \multirow[t]{3}{*}{ Desperdício de água } & Aumento do volume demandado de água \\
\hline & & Redução da disponibilidade de água \\
\hline & & Aumento no risco de escassez hídrica \\
\hline \multirow{7}{*}{$\begin{array}{l}\text { Abastecimento doméstico } \\
\text { no meio rural }\end{array}$} & \multirow{2}{*}{$\begin{array}{c}\text { Utilização de água/Consumo de } \\
\text { água }\end{array}$} & Redução da disponibilidade de água \\
\hline & & Aumento do risco de escassez hídrica \\
\hline & \multirow[t]{4}{*}{ Utilização de produtos químicos } & Poluição hídrica \\
\hline & & Contaminação hídrica \\
\hline & & Eutroficação (detergentes, sabão etc.) \\
\hline & & Risco de alteração na qualidade da água \\
\hline & Destinação ambientalmente e & Poluição hídrica \\
\hline
\end{tabular}




\begin{tabular}{|c|c|c|}
\hline & & (Conc \\
\hline \multirow[t]{9}{*}{$\begin{array}{c}\text { Atividade } \\
\text { Empreendimento }\end{array}$} & Aspecto ambiental & Impacto ambiental na água ${ }^{1}$ \\
\hline & \multirow{8}{*}{$\begin{array}{c}\text { inadequada de resíduos sólidos } \\
\text { líquidos }\end{array}$} & Contaminação hídrica \\
\hline & & Eutroficação \\
\hline & & Alteração na paisagem natural do rio \\
\hline & & Poluição visual nas águas do rio \\
\hline & & Aumento da turbidez \\
\hline & & Efeitos de odores desagradáveis \\
\hline & & Alteração na qualidade da água \\
\hline & & Limitação de uso da água para fins mais nobres \\
\hline \multirow{9}{*}{$\begin{array}{l}\text { Criação de camarão de } \\
\text { água doce }\end{array}$} & \multirow{2}{*}{$\begin{array}{l}\text { Utilização de água } \\
\text { Consumo de água }\end{array}$} & Redução da disponibilidade de água \\
\hline & & Aumento no risco de escassez hídrica \\
\hline & \multirow{7}{*}{$\begin{array}{c}\text { Destinação ambientalmente } \\
\text { inadequada de resíduos sólidos e } \\
\text { líquidos na água }\end{array}$} & Poluição hídrica \\
\hline & & Contaminação hídrica \\
\hline & & Eutroficação \\
\hline & & Aumento da turbidez \\
\hline & & Efeitos de odores desagradáveis \\
\hline & & Alteração na qualidade da água \\
\hline & & Poluição hídrica \\
\hline \multirow{7}{*}{$\begin{array}{l}\text { Estabelecimentos } \\
\text { comerciais em áreas } \\
\text { rurais }\end{array}$} & \multirow{7}{*}{$\begin{array}{l}\text { Lançamento de resíduos sólidos } \\
\text { e líquidos }\end{array}$} & Poluição hídrica \\
\hline & & Contaminação hídrica \\
\hline & & Eutroficação \\
\hline & & Efeitos de odores desagradáveis \\
\hline & & Poluição visual nas águas do rio \\
\hline & & Alteração na paisagem natural do rio \\
\hline & & Alteração na qualidade da água \\
\hline
\end{tabular}

${ }^{1}$ Apesar de ter sido feita a identificação dos impactos apenas no fator ambiental "água", conforme o objetivo principal deste estudo, sabe-se que outros fatores ambientais são alterados de forma direta ou indireta por parte das (dos) atividades/empreendimentos na área de estudo.

Fonte: Autoria própria, 2015.

Como pode ser observado no Quadro 4, foram identificados 132 impactos ambientais nas águas do trecho perenizado do rio Piancó, sendo que, ao se contabilizar os impactos "recorrentes" em parte das(os) diferentes atividades/empreendimentos, tem-se um total de 22 tipos de impactos.

Dentre os impactos identificados na água da área estudada, destacam-se: a poluição e contaminação hídrica, a eutroficação, o aumento da turbidez e a alteração 
na qualidade da água, que foram ocasionados com maior frequência pelas atividades antrópicas verificadas. Parte destes impactos foram também identificados por Ramos et al. (2016) que, ao avaliarem os impactos ambientais sob o rio Espinharas, no município de Patos (PB), destacaram o crescimento populacional como um fator que potencializa a propagação dos impactos ambientais identificados.

Cabe ressaltar ainda que a água do rio Piancó é consumida pela população para consumo humano, seja para beber, preparar alimentos, higiene pessoal e outros fins. De acordo com Santos (2005), o contato direto com a água com riscos potenciais de poluição e/ou contaminação pode expor as pessoas a algum tipo de contaminação e favorecer a proliferação de doenças.

Pinheiro et al. (2014) também constataram que as atividades antrópicas, sejam elas a urbanização, a disposição inadequada de efluentes ou outras atividades com potencial impactante comprometem a qualidade da água.

Diante disso, percebe-se a necessidade da adoção de ações voltadas para controlar os impactos ambientais identificados, tendo em vista a melhoria da qualidade ambiental da área de estudo.

\section{CONSIDERAÇÕES FINAIS}

A agricultura foi a atividade antrópica de maior predominância na área de estudo;

Foram identificados 132 impactos ambientais na área de influência do estudo, sendo que a atividade antrópica "responsável" pelo maior número de impactos ambientais foi a urbanização;

Os impactos ambientais mais constatados foram a poluição e a contaminação hídrica, a eutroficação, o aumento da turbidez e a alteração na qualidade da água;

Percebe-se a necessidade da adoção de ações voltadas para controlar os impactos ambientais identificados, tendo em vista a melhoria da qualidade ambiental da área de estudo. 


\section{REFERÊNCIAS}

AESA. Agência Executiva de Gestão das Águas do Estado da Paraíba. Disponível em: http://www.aesa.pb.gov.br/geoprocessamento/geoportal/mapas.html. Acesso em: 05 out. 2015.

ANA. Panorama da qualidade das águas superficiais do Brasil. Agência Nacional de Águas. Brasília: ANA, 2012, 264 p.

BARROS, F. G. N.; AMIN, M. M. Água: um bem econômico de valor para o Brasil e o mundo. Revista Brasileira de Gestão e Desenvolvimento Regional. Taubaté. v. 4, n. 1, p. 75-108, jan./abr. 2008.

BRASIL. Resolução CONAMA no 001, de 23 de janeiro de 1986. Diário Oficial da União, Poder Executivo, Brasília. Dispõe sobre critérios básicos e diretrizes gerais para a avaliação de impacto ambiental. 1986, 4p.

BRASIL. Resolução CONAMA no 357, de 17 de março de 2005. Diário Oficial da União, Poder Executivo, Brasília. Dispõe sobre a classificação dos corpos de água e diretrizes ambientais para o seu enquadramento. 2005, 27p.

CPRM. Projeto cadastro de fontes de abastecimento por água subterrânea: diagnóstico do município de Cajazeirinhas. Companhia de Pesquisa de Recursos Minerais. Recife: CPRM/PRODEEM, 2005a, 19p.

CPRM. Projeto cadastro de fontes de abastecimento por água subterrânea: diagnóstico do município de Coremas. Companhia de Pesquisa de Recursos Minerais. Recife: CPRM/PRODEEM, 2005b, 21p.

CPRM. Projeto cadastro de fontes de abastecimento por água subterrânea: diagnóstico do município de Pombal. Companhia de Pesquisa de Recursos Minerais. Recife: CPRM/PRODEEM, 2005c, 23p.

CUNHA, B. C.; GUERRA, A. J. T. Avaliação e perícia ambiental. 10. ed. Rio de Janeiro: Bertrand Brasil, 2010, 286p.

EMBRAPA. Solos do Nordeste. Empresa Brasileira de Pesquisa Agropecuária. Dis- 
ponível em: http://www.uep.cnps.embrapa.br/solos/index.php?link=pb. Acesso em: 23 out. 2015.

FOGLIATTI, M. C.; FILIPPO, S.; GOUDARD, B. Avaliação de impactos ambientais: aplicação aos sistemas de transporte. Rio de Janeiro: Interciência, 2004, 249p.

IBGE. Banco de dados agregados: censo demográfico. Instituto Brasileiro de Geografia e Estatística - IBGE: Brasil, 2010. Disponível em: http://www.sidra.ibge. gov.br/bda/popul/default.asp?t $=3 \& \mathrm{z}=\mathrm{t} \& \mathrm{o}=25 \& \mathrm{u} 1=1 \& \mathrm{u} 2=1 \& \mathrm{u} 3=1 \& \mathrm{u} 4=1 \& \mathrm{u} 5$ $=1 \& u 6=1$. Acesso em: 23 mar. 2015 .

LIMA, F. C.; LEITE, J. C. A. Estudo de avaliação e diagnóstico dos impactos ambientais resultantes da implantação do Campus Universitário da UFCG em Pombal-PB. Projeto PIBIC. Pombal, 2011, 21p.

PEREIRA, R. S. Identificação e caracterização das fontes de poluição em sistemas hídricos. Revista Eletrônica de Recursos Hídricos. Porto Alegre. v. 1, n. 1, p. 2036, jul./set. 2004.

PINHEIRO, A.; SCHOEN, C.; SCHULTZ, J.; HEINZ, K. G. H.; PINHEIRO, I. G.; DESCHAMPS, F. C. Relação entre o uso do solo e a qualidade da água em bacia hidrográfica rural no bioma mata atlântica. Revista Brasileira de Recursos Hídricos, Porto Alegre, v. 19, n. 3, p. 127-139, jul./set. 2014.

RAMOS, G. G. et al. Levantamento dos impactos ambientais de um trecho de mata ciliar em região de Caatinga no sertão paraibano. In: I CONGRESSO INTERNACIONAL DA DIVERSIDADE DO SEMIÁRIDO, 1., Campina Grande. Anais [...]. 2016.

SÁNCHEZ, L. E. Avaliação de impacto ambiental: conceitos e métodos. São Paulo: Oficina de Textos, 2008, 495p.

SANTOS, A. S. Diagnóstico socioambiental e identificação dos impactos ambientais ao longo do Rio Araçagi-PB. 2009. 144f. Dissertação (Geografia) - Universidade Federal da Paraíba - UFPB, João Pessoa, 2009.

SUDEMA. Programa: monitoramento de corpos d'água. Superintendência de Administração do Meio Ambiente, Sede de João Pessoa, 2014. 
VANZELA, L. S.; HERNANDEZ, F. B. T.; FRANCO, R. A. M. Influência do uso e ocupação do solo nos recursos hídricos do Córrego Três Barras, Marinópolis. Revista Brasileira de Engenharia Agrícola e Ambiental, Campina Grande. v. 14, n. 1, 2010, p. 55-64.

Recebido em: 01/03/2018

Aceito em: 24/05/2018 